\title{
Desempenho agronômico do alho-porró em diferentes densidades populacionais
}

\author{
Agronomic performance of leeks in different population densities \\ Comportamiento agronómico de puerros en diferentes densidades de población
}

Recebido: 22/01/2021 | Revisado: 31/01/2021 | Aceito:02/02/2021 | Publicado: 07/02/2021

\author{
Pablo Wenderson Ribeiro Coutinho \\ ORCID: https://orcid.org/0000-0002-4945-3161 \\ Doutor pesquisador autônomo, Brasil \\ E-mail: pablowenderson@ hotmail.com \\ Márcia de Moraes Echer \\ ORCID: https://orcid.org/0000-0003-4691-4273 \\ Universidade Estadual do Oeste do Paraná, Brasil \\ E-mail: marcia.echer@unioeste.br \\ Karina Kestring \\ ORCID: https://orcid.org/0000-0002-9018-0839 \\ Universidade Estatual do Oeste do Paraná, Brasil \\ E-mail: kaakestring@ hotmail.com \\ Rayssa Helana da Silva \\ ORCID: https://orcid.org/0000-0001-7471-3900 \\ Universidade Estatual do Oeste do Paraná, Brasil \\ E-mail: ray.helana@hotmail.com \\ Amanda Sabino do Nascimento \\ ORCID: https://orcid.org/0000-0003-4256-5539 \\ Universidade Estadual de Maringá, País \\ E-mail: amandasabinonascimento@ outlook.com
}

\begin{abstract}
Resumo
O alho-porró (Allium porrum L.) pertence à família Aliáceae, um grupo de grande importância econômica, pois além desta espécie estão presentes a cultura da cebola, cebolinha e outras variedades de alho. Pouco se conhece sobre o seu crescimento e desenvolvimento, no entanto sabe-se que o desenvolvimento vegetativo de uma planta varia em função das características intrínsecas de cada espécie ou cultivar, das condições meteorológicas de cada safra e do ambiente de cultivo, bem como das práticas agrícolas adotadas. Desta forma o objetivo deste trabalho foi determinar a influência do espaçamento entre plantas e linha em relação as características vegetativas e produtivas de alho-porró. O delineamento utilizado foi de blocos ao acaso com quatro repetições, distribuídos em: 0,50 x 0,25 m; 0,50 x 0,20 m; $0,50 \times 0,15 \mathrm{~m} ; 0,50 \times 0,10 \mathrm{~m} ; 0,40 \times 0,15 \mathrm{~m} ; 0,40 \times 0,10 \mathrm{~m} ; 0,30 \times 0,20 \mathrm{~m}$ e $0,30 \times 0,15 \mathrm{~m}$. Realizou-se avaliações quando as plantas chegaram ao seu máximo desenvolvimento vegetativo: altura da planta $(\mathrm{cm})$, altura do pseudocaule $(\mathrm{cm})$, diâmetro do pseudocaule $(\mathrm{mm})$, massa fresca da parte aérea $(\mathrm{g})$, número de folhas, área foliar $\left(\mathrm{cm}^{2}\right)$, massa seca das folhas (g), massa seca do pseudocaule (g) e produtividade. Os espaçamentos não interferiram para as variáveis de altura de planta, número de folha e área foliar, porém para as variáveis produtivas da cultura do alho-porró foram influenciados pelo espaçamento entre plantas e linhas. Desta forma, com base nos resultados obtidos, recomenda-se a utilização dos espaçamentos $0,50 \times 0,10 \mathrm{~m}$ e $0,30 \times 0,15 \mathrm{~m}$, devido proporcionarem aumento de produtividade para a cultura do alho-porró.
\end{abstract}

Palavras-chave: Allium ampeloprasum L.; Pseudocaule; Produtividade; Densidade e competição intraespecífica.

\begin{abstract}
The leek (Allium porrum L.) belongs to the Aliáceae family, a group of great economic importance, besides the species there are also onion, chives and other garlic varieties. There's not so much knowledge about its growth and development, however, it is known that the vegetative development of a plant varies depending on the intrinsic characteristics of each species or cultivar, the weather conditions of each crop and the cultivation environment, as well as the practices agricultural adopted. Considered that, the objective of the work was to determine if the affected spacing between plants and lines in relation to the vegetative and productive characteristics of leeks. The design used was a randomized block with four replications, distributed in: $0.50 \times 0.25 \mathrm{~m} ; 0.50 \times 0.20 \mathrm{~m} ; 0.50 \times 0.15 \mathrm{~m} ; 0.50 \times$ $0.10 \mathrm{~m} ; 0.40 \times 0.15 \mathrm{~m} ; 0.40 \times 0.10 \mathrm{~m} ; 0.30 \times 0.20 \mathrm{~m}$ and $0.30 \times 0.15 \mathrm{~m}$. Assessments were carried out when the plants reached their maximum vegetative development: plant height $(\mathrm{cm})$, pseudostem height $(\mathrm{cm})$, pseudostem diameter $(\mathrm{mm})$, fresh shoot weight $(\mathrm{g})$, number of leaves, leaf area $\left(\mathrm{cm}^{2}\right)$, dry leaf weight $(\mathrm{g})$, pseudostem dry weight $(\mathrm{g})$ and productivity. The spacing did not interfere with the variables of plant height, number of leaves, and leaf area, however, the productivity variables of the leek culture were influenced by the spacing between plants and lines. Thus, based on the results obtained, it is recommended to use the $0.50 \times 0.10 \mathrm{~m}$ and $0.30 \times 0.15 \mathrm{~m}$ spacings, due to the increased productivity for the leek culture.
\end{abstract}


Keywords: Allium ampeloprasum L.; Pseudostem; Productivity; Density and intaspecific competition.

\section{Resumen}

El puerro (Allium porrum L.) pertenece a la familia de las Aliáceae, un grupo de gran importancia económica, ya que además de esta espécie también existen cebollas, cebolletas y otras variedades de ajo. Poco se sabe sobre su crecimiento y desarrollo, sin embargo se sabe que el desarrollo vegetativo de uma planta varía dependiendo de las características intrínsecas de cada especie o cultivar, las condiciones climáticas de cada cultivo y el ambiente de cultivo, así como las prácticas agrícola adoptado. Así, el objetivo de este trabajo fue determinar la influencia del espaciamiento entre plantas y línea en relación a las características vegetativas y productivas del puerro. El diseño utilizado fue un bloque al azar con cuatro repeticiones, distribuidas en: $0,50 \times 0,25 \mathrm{~m} ; 0,50 \times 0,20 \mathrm{~m} ; 0,50 \times 0,15 \mathrm{~m}$; $0,50 \times 0,10 \mathrm{~m} ; 0,40 \times 0,15 \mathrm{~m} ; 0,40 \times 0,10 \mathrm{~m} ; 0,30 \times 0,20 \mathrm{~m}$ y $0,30 \times 0,15 \mathrm{~m}$. Las evaluaciones se realizaron cuando las plantas alcanzaron su máximo desarrollo vegetativo: altura de la planta $(\mathrm{cm})$, altura del pseudotallo (cm), diámetro del pseudotallo $(\mathrm{mm})$, peso del brote fresco $(\mathrm{g})$, número de hojas, área foliar $\left(\mathrm{cm}^{2}\right)$, peso de hoja seca $(\mathrm{g})$, peso seco del pseudotallo (g) y productividad. El espaciamiento no interfirió para las variables altura de la planta, número de hojas y área foliar, sin embargo para las variables productivas del cultivo de puerros influyó el espaciamiento entre plantas y líneas. Así, en base a los resultados obtenidos, se recomienda utilizar los espaciamientos de 0,50 x 0,10 m y 0,30 x $0,15 \mathrm{~m}$, ya que proporcionan una mayor productividad para el cultivo de puerros.

Palabras clave: Allium ampeloprasum L.; Pseudocaule; Productividad; Densidad e competencia intraespecífica.

\section{Introdução}

O alho-porró (Allium ampeloprasum var. porrum L.) pertence à família Aliáceae, um grupo de grande importância econômica, pois além desta espécie estão presentes a cultura da cebola, cebolinha e outras variedades de alho (Yousaf et al., 2004; Stavělíková, 2008). Conhecido também por alho-macho, alho francês ou alho-porró, tem sabor mais apreciável por ser delicado e suavemente adocicado, sendo sua produção concentrada na região sul e sudeste do Brasil (Embrapa, 2010).

A cultura é muito exigente em fotoperíodo e temperatura para o seu completo desenvolvimento, apresentando menos tolerante ao calor em relação as outras aliáceas, sendo mais propícias para seu cultivo temperaturas variando entre $13{ }^{\circ} \mathrm{C}$ e 25 ${ }^{\circ} \mathrm{C}$, constituindo uma característica importante do alho-porró a alta resistência ao frio. As condições ideais do solo para o cultivo da planta são textura média e fértil, bem drenado e boa capacidade de retenção de água, com o pH indicado entre 6,0 e 6,8 (Filgueira, 2013).

A planta e herbácea, apresentando uma estrutura alongada e branca que lembra as culturas do alho e da cebola, porém é mais vigorosa. Forma um pseudocaule alongado, que pode se estiolado ficando branco comumente chamado de talo que pode alcançar de 10 a $20 \mathrm{~cm}$ de comprimento e até $6 \mathrm{~cm}$ de diâmetro, além de apresenta folhas mais largas e alongadas de coloração esverdeada (Filgueira, 2013).

O produto comercializado do alho-porró é o seu pseudocaule, sendo que seu rendimento varia de acordo com a cultivar, fotoperíodo, densidade de plantio e manejo da cultura (Kiffo et al., 2016). Pouco se conhece sobre o crescimento e desenvolvimento do alho-porró, no entanto sabe-se que o desenvolvimento vegetativo de uma planta varia em função das características intrínsecas de cada espécie ou cultivar, das condições meteorológicas de cada safra e do ambiente de cultivo, bem como das práticas agrícolas adotadas.

O aumento de produção é influenciado pelo manejo de plantas, pois este e um dos fatores que podem ser correlacionados positivamente com a porcentagem de interceptação de luz pelas folhas da cultura. Para um bom funcionamento do metabolismo vegetal, e necessário que o mesmo consiga absorver luz de qualidade, que chegue nos centros de reações que vão converter em produtos fotossintéticos, influenciando assim a produtividade da cultura (Abade et al., 2019).

Dentre as condições que influenciam o aumento da produção, está o número de plantas por unidade de área, para isso devem-se buscar as melhores práticas de cultivo, com o uso adequado dos espaçamentos em hortaliças (Almeida et al., 2020; Costa et al., 2020; Vidigal et al., 2020). O adensamento de cultivo pode proporcionar um sombreamento parcial em algumas plantas, influenciando diretamente nos danos da cultura, pois vai ocasionar uma competição intraespecífica e interespecífica 
pelos fatores de produção (luz, água, nutrientes e $\mathrm{CO}_{2}$ ), ocasionando assim a redução considerável do crescimento e desenvolvimento da cultura, o que vem diminuir drasticamente a produtividade (Alves et al., 2020).

Os trabalhos realizados com espaçamentos entre plantas e linhas, tem como objetivo de ser ter uma uniformização das plantas na área de cultivo, permitindo assim uma maior eficiência da exploração dos elementos disponíveis no ambiente, tais como água, luz e nutrientes (Bezerra et al., 2014). Pois espaçamento vai refletir nas características fisiológicas e morfológicas da planta, alterando assim a arquitetura da planta, produtividade e qualidade do produto final (Resende et al., 2016).

Desta forma, para se obter o melhor aproveitamento do espaço físico, e necessário primeiramente conhecer a capacidade produtiva da espécie que vai ser estudada quando submetida a diferentes densidades populacionais de plantas, o que poderá determinar a densidade ideal para plantio, onde a planta vai expressar todo o seu potencial produtivo (Favorito et al., 2011; Vasconcelos et al., 2017; Lima et al., 2019). A densidade ideal de plantio é fundamental para minimizar os efeitos da interferência que plantas daninhas possam causar na cultura principal (Batista et al., 2015).

Considerando que o ambiente de cultivo pode influenciar nas características produtivas de uma cultura, este trabalho teve como objetivo determinar a influência do espaçamento entre plantas e linha em relação as características vegetativas e produtivas de alho-porró.

\section{Metodologia}

O experimento foi conduzido a campo no período de agosto de 2015 a janeiro de 2016, na Estação Experimental Prof.

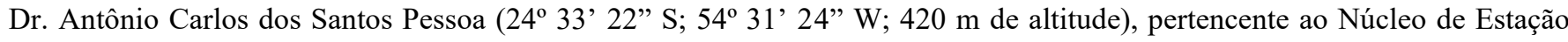
Experimental da Universidade Estadual do Oeste do Paraná (UNIOESTE), município de Marechal Cândido Rondon, Paraná. O clima da região é do tipo Cfa subtropical mesotérmico úmido de inverno seco, com chuvas bem distribuídas durante todo o ano e verões quentes, segundo a classificação de Köppen (Alvares et al., 2013). Os dados meteorológicos referentes ao período experimental foram obtidos na Estação Meteorológica de Observação de Superfície Automática de Marechal Cândido Rondon (Figura 1).

Figura 1 - Temperatura mínima, máxima e média do ar e umidade relativa do ar por dia, durante a condução do experimento realizado em Marechal Cândido Rondon - PR.

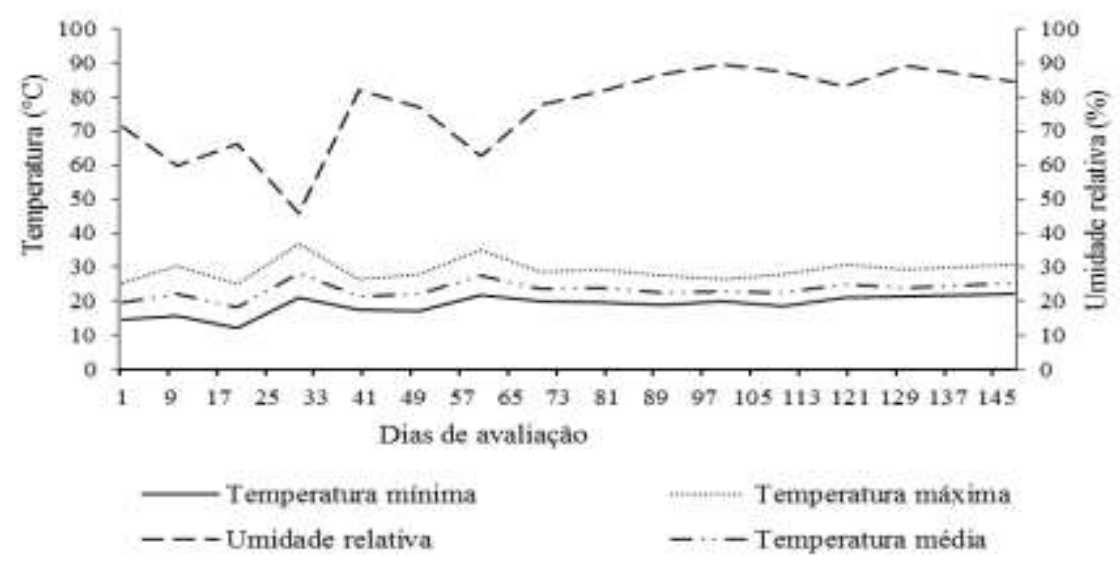

Fonte: Autores.

O solo predominante é do tipo LATOSSOLO VERMELHO eutroférrico de textura argilosa, com as seguintes características químicas na camada de 0 a 0,20 m: $\mathrm{pH}\left(\mathrm{CaCl}_{2}\right)=5,85 ; \mathrm{MO}=24,61 \mathrm{~g} \mathrm{dm}^{-3} ; \mathrm{P}\left(\right.$ Mehlich 1) $=134,20 \mathrm{mg} \mathrm{dm}^{-3} ; \mathrm{K}$ 
$\left(\right.$ Mehlich 1) $=0,85 \mathrm{cmol}_{\mathrm{c}} \mathrm{dm}^{-3} ; \mathrm{Ca}^{2+}=5,19 \mathrm{cmol}_{\mathrm{c}} \mathrm{dm}^{-3} ; \mathrm{Mg}^{2+}=3,70 \mathrm{cmol}_{\mathrm{c}} \mathrm{dm}^{-3} ; \mathrm{Al}^{3+}=0 \mathrm{cmol}_{\mathrm{c}} \mathrm{dm}^{-3} ; \mathrm{SB}^{2}=9,74 \mathrm{cmol}_{\mathrm{c}} \mathrm{dm}^{-3}$; $\mathrm{CTC}=12,59 \mathrm{cmol}_{\mathrm{c}} \mathrm{dm}^{-3} ; \mathrm{H}+\mathrm{Al}=2,55 \mathrm{cmol}_{\mathrm{c}} \mathrm{dm}^{-3} \mathrm{e} \mathrm{V}=77,36 \%$.

O delineamento experimental utilizado foi em blocos casualizados, com quatro repetições e oito espaçamentos entre plantas e entre linhas, totalizando 32 unidades experimentais, sendo composto por 18 plantas por parcela distribuídas em canteiros de quatro linhas, utilizando para avaliação as duas linhas centrais da parcela, eliminando-se as extremidades. Os tratamentos foram constituídos pelos espaçamentos entre plantas e entre linhas: 0,50 x 0,25 m; 0,50 x 0,20 m; 0,50 x 0,15 m; $0,50 \times 0,10 \mathrm{~m} ; 0,40 \times 0,15 \mathrm{~m} ; 0,40 \times 0,10 \mathrm{~m} ; 0,30 \times 0,20 \mathrm{~m}$ e $0,30 \times 0,15 \mathrm{~m}$.

As mudas foram produzidas em bandejas de 200 células, contendo substrato agrícola comercial. Estas foram mantidas em ambiente protegido, sendo irrigadas conforme a necessidade até o transplante para o campo que ocorreu aos 48 dias após a semeadura.

A adubação de plantio e cobertura foram realizadas de acordo com análise solo e com as recomendações de Raij (2011), sendo modificado a quantidade conforme a população de plantas. A irrigação foi realizada por aspersão duas vezes ao dia, já os demais tratos culturais foram realizados conforme a necessidade da cultura.

A avaliação foi realizada aos 120 dias após o transplante, quando as plantas atingiram seu máximo desenvolvimento vegetativo, sendo avaliado: a altura da planta (a partir do nível do solo até a extremidade da folha mais alta), altura do pseudocaule, diâmetro do pseudocaule, massa fresca da parte aérea, número de folhas, área foliar, massa seca das folhas, massa seca do pseudocaule.

Para a determinação das alturas foi utilizado uma trena graduada, já o diâmetro foi feito com o auxílio de um paquímetro digital - medidas realizadas na base. As massas secas das diferentes partes das plantas foram acondicionadas em sacos de papel e secas em estufa de circulação forçada de ar a $65 \pm 5^{\circ} \mathrm{C}$, até atingirem massa constante. Posteriormente, as partes da planta foram pesadas em balança de precisão e calculada a massa seca total. A área foliar foi determinado por meio do aparelho Area Meter da marca Li-cor, modelo 3100C. A produtividade foi estimada com base na massa fresca das quatro plantas avaliadas no momento da colheita, expressa em $\mathrm{kg} \mathrm{ha}^{-1}$.

Os dados experimentais foram tabulados e submetidos ao teste de normalidade Shapiro-Wilk ( $\mathrm{p} \leq 0,05)$. Em seguida, procedeu-se à análise variância e as médias comparadas pelo teste de Tukey $(\mathrm{p} \leq 0,05)$, mediante a utilização do software estatístico SISVAR (Ferreira, 2019).

\section{Resultados e Discussão}

A temperatura média no decorrer do trabalho foi amena, apresentando entre 18,10 a $27,60^{\circ} \mathrm{C}$ (Figura 1), contribuindo assim para o melhor desenvolvimento da parte aérea. Pois sabe se que o alho-porró e uma planta típica de clima frio, sendo uma cultura muito exigente em fotoperíodo e temperatura no decorrer do seu ciclo, sendo menos tolerante ao calor em relação as outras aliáceas (Filgueira, 2013).

A altura da planta, número de folhas, área foliar e massa seca da parte aérea da planta não apresentaram diferença significativa entre os espaçamentos entre plantas e linhas testados (Tabela 1). Demostrando que essas características são inerentes a cultivar testada, onde o espaçamento não influenciou nas variáveis morfológicas, como foi observado no estudo de Almeida et al. (2020) com rabanete e no trabalho com variabilidade genética em genótipos de couve de Azevedo et al. (2012). 
Tabela 1. Altura de planta (APL), número de folhas (NF), área foliar (AF), massa seca da parte aérea (MSPA) e massa seca do pseudocaule (MSPC) para o alho-porró cultivado em diferentes espaçamentos - Marechal Cândido Rondon-PR em 2015.

\begin{tabular}{lccccc}
\hline \multicolumn{1}{c}{ Tratamentos } & APL $(\mathrm{cm})$ & NF & AF $\left(\mathrm{cm}^{2}\right)$ & MSPA $(\mathrm{g})$ & MSPC $(\mathrm{g})$ \\
\hline $0,50 \times 0,15$ & 72,63 & 10,5 & 1408,75 & 21,67 & $13,67 \mathrm{ab}$ \\
$0,50 \times 0,20$ & 80,75 & 10 & 1375,5 & 23,56 & $13,07 \mathrm{ab}$ \\
$0,50 \times 0,25$ & 68,88 & 9,63 & 1208,38 & 25,27 & $12,62 \mathrm{ab}$ \\
$0,50 \times 0,10$ & 89,75 & 10,25 & 1472,5 & 21,18 & $13,45 \mathrm{ab}$ \\
$0,40 \times 0,15$ & 81,63 & 10,63 & 1297,25 & 18,1 & $16,38 \mathrm{a}$ \\
$0,40 \times 0,10$ & 81,75 & 8,75 & 1292,5 & 17,31 & $8,47 \mathrm{~b}$ \\
$0,30 \times 0,20$ & 70,75 & 10,38 & 1416,88 & 26,64 & $12,07 \mathrm{ab}$ \\
$0,30 \times 0,15$ & 101,25 & 10,38 & 1260 & 26,66 & $9,81 \mathrm{ab}$ \\
\hline CV $(\%)$ & 18,69 & 17,17 & 13,15 & 30,07 & 24,87 \\
DMS & 35,85 & 4,1 & 418,47 & 16,08 & 7,34 \\
\hline
\end{tabular}

Médias seguidas de mesma letra nas colunas não diferem estatisticamente entre si, teste de Tukey, $\mathrm{p}<0,05$. Fonte: Autores.

A maior densidade populacional de plantas pode ocasionar uma competição interespecífica por luz, onde as plantas vão gastar energia para o crescimento, alterando assim a arquitetura da planta, podendo ocasionar um auto sombreamento em algumas plantas, o que vem reduzir a intensidade luminosa, processo fotossintético e consequentemente a produção da cultura (Resende et al., 2016; Taiz et al., 2017). O que não foi observado no estudo em relação as características de altura de planta, número de folhas, área foliar e massa seca da parte aérea da planta, quando os fatores extrínsecos como o manejo da densidade populacional de plantas foram alterados.

O número de folhas e área foliar são características morfométricas que se correlacionam com a massa fresca de folhas da planta, pois essa produção de biomassa está associada com a capacidade de assimilação fotossintética do carbono, que é responsável por cerca de $90 \%$ da massa seca do material vegetal (Taiz et al., 2017). Devido a esse motivo não se constatou diferença significativa para massa seca da parte aérea da planta.

Embora que não se tenha demostrando diferença na massa seca da planta, a parte mais importante do alho-porró é o pseudocaule, pois este e a parte comercializada e seu rendimento pode ser alterado de acordo com a cultivar estudada, fotoperíodo, densidade de plantio e manejo da cultura (Kiffo et al., 2016; Coutinho et al., 2017; Coutinho et al., 2018; Abade et al., 2019; Almeida et al., 2020).

$\mathrm{O}$ espaçamento que proporcionou a melhor massa seca do pseudocaule foi 0,40 x $0,15 \mathrm{~m}(16,38 \mathrm{~g})$ e o que apresentou uma redução considerável dessa massa foi $0,40 \times 0,10 \mathrm{~m}(8,47 \mathrm{~g})$. Os valores baixos de matéria seca observados nos menores espaçamentos, ocorreu devido à competição entre plantas por recursos ambientais como luz, água, nutrientes e $\mathrm{CO}_{2}$. O mesmo resultado foi observado por Almeida et al. (2020), trabalhando com espaçamento entre plantas de rabanete.

Menores espaçamentos proporcionam menores médias de massa fresca e seca, este fato pode ser explicado devido a redução da área foliar ocupada pela planta, embora que a mesma não tenha demostrando diferença estatística, ainda a uma competição pelos recursos ambientais e que vai aumentar a competição para o crescimento radicular, que consequentemente vai acabar reduzido e prejudicando a produtividade da cultura. O mesmo resultado foi observado por Vasconcelos et al. (2017), trabalhando com o efeito residual de esterco de ovinos no cultivo de alface em diferentes espaçamentos. 
Para as variáveis altura do pseudocaule, diâmetro pseudocaule, massa fresca da parte aérea e produtividade de alhoporró, foram influenciados pelos espaçamentos (Tabela 2). Demostrando que de fato o espaçamento entre plantas e linhas, pode aumentar ou reduzir as características produtivas do alho-porró.

Tabela 2. Altura do pseudocaule (APC), diâmetro do pseudocaule (DPC), massa fresca da parte aérea (MFPA) e produtividade (PROD) do alho-porró cultivado em diferentes espaçamentos - Marechal Cândido Rondon-PR em 2015.

\begin{tabular}{lcccc}
\hline \multicolumn{1}{c}{ Tratamentos } & APC $(\mathrm{cm})$ & DPC $(\mathrm{mm})$ & MFPA $(\mathrm{g})$ & PROD $\left(\mathrm{kg} \mathrm{ha}^{-1}\right)$ \\
\hline $0,50 \times 0,15$ & $13,93 \mathrm{ab}$ & $36,63 \mathrm{a}$ & $0,3175 \mathrm{a}$ & $42008 \mathrm{ab}$ \\
$0,50 \times 0,20$ & $11,21 \mathrm{~b}$ & $27,11 \mathrm{bc}$ & $0,3275 \mathrm{a}$ & $32500 \mathrm{bc}$ \\
$0,50 \times 0,25$ & $14,48 \mathrm{ab}$ & $31,02 \mathrm{abc}$ & $0,2550 \mathrm{ab}$ & $20385 \mathrm{c}$ \\
$0,50 \times 0,10$ & $15,90 \mathrm{ab}$ & $32,47 \mathrm{ab}$ & $0,2625 \mathrm{ab}$ & $52525 \mathrm{a}$ \\
$0,40 \times 0,15$ & $17,90 \mathrm{ab}$ & $31,72 \mathrm{abc}$ & $0,2650 \mathrm{a}$ & $44031 \mathrm{ab}$ \\
$0,40 \times 0,10$ & $12,90 \mathrm{ab}$ & $27,30 \mathrm{bc}$ & $0,1675 \mathrm{~b}$ & $42059 \mathrm{ab}$ \\
$0,30 \times 0,20$ & $13,38 \mathrm{ab}$ & $27,13 \mathrm{bc}$ & $0,2700 \mathrm{a}$ & $44458 \mathrm{ab}$ \\
$0,30 \times 0,15$ & $12,21 \mathrm{~b}$ & $23,63 \mathrm{c}$ & $0,2550 \mathrm{ab}$ & $56972 \mathrm{a}$ \\
\hline CV $(\%)$ & 15,24 & 11,73 & 15,38 & 17,44 \\
DMS & 5,06 & 8,24 & 0,0967 & 17320 \\
\hline
\end{tabular}

Médias seguidas de mesma letra nas colunas não diferem estatisticamente entre si, teste de Tukey, $\mathrm{p}<0,05$. Fonte: Autores.

A altura do pseudocaule e uma característica importante no que se refere aos consumidores de alho-porró, pois na hora da compra há procura dos pseudocaules maiores. Em relação ao o estudo, os tratamentos que apresentaram menores alturas foram $0,50 \times 0,20 \mathrm{~m}$ e $0,30 \times 0,15 \mathrm{~m}$, expondo que esses espaçamentos entre plantas e linhas influenciaram na fisiologia do desenvolvimento da cultura, prejudicando assim o transporte de nutrientes e energias que são essências para o incremento do pseudocaule. Os demais espaçamentos apresentam alturas superiores aos mencionados, remetendo novamente aos consumidores que na hora de comprar o alho-porró, os mesmos preferem os talos maiores.

$\mathrm{O}$ aumento do adensamento de plantas pode causar o estiolamento da cultura, proveniente da competição por luz, o que vem causar o crescimento excessivo do caule, promovendo a redução momentânea do desenvolvimento radicular (Sampaio et al., 2018). Para o alho-porró este estiolamento do pseudocaule vai resultar em aumento de produtividade, além de torná-lo branco o que pode aumentar a sua qualidade visual, pois a parte comercializável desta cultura e o próprio pseudocaule, porém este estiolamento pode ocorrer em período que a planta ainda não tenha demostrando todo o seu potencial no desenvolvimento, devido o adensamento de plantas, o que pode resultar em talos finos o que vem reduzir a qualidade do produto final.

O diâmetro do pseudocaule e uma característica que está associada à altura do mesmo, pois os consumidores deste produto buscam talos grandes com maiores diâmetros, apresentando uma aparência de boa qualidade. Os espaçamentos entre plantas e linhas que proporcionaram maiores diâmetro foi de $0,50 \times 0,15 \mathrm{~m}$, já o espaçamento 0,30 x $0,15 \mathrm{~m}$ expôs menores diâmetros sendo influenciado desta assim pelo espaçamento entre linhas, pois o entre plantas foi o mesmo utilizado para se obter maiores diâmetros.

O espaçamento $0,40 \times 0,10 \mathrm{~m}$ proporcionou uma redução da MFPA do alho-porró, demostrando que houve uma competição intraespecífica, ou seja, o adensamento do espaçamento entre plantas e linhas interferiu no desenvolvimento, 
causando uma redução do número de folhas por planta e a área foliar do mesmo, embora que essas variáveis não tenha demostrado diferença estatística ao demais tratamentos, apresentaram uma redução notável.

A massa fresca da parte aérea da planta apresentou uma redução para este tratamento, devido a ocorrência do auto sombreamento umas sobre as outras, além de aumentar a competição por luz, água, nutrientes e $\mathrm{CO}_{2}$. $\mathrm{O}$ adensamento vem influenciar diretamente no desenvolvimento da cultura, causando danos o que vem reduzir drasticamente a sua massa fresca e consequentemente sua produtividade (Alves et al., 2020).

Embora que o adensamento entre plantas reduziu a massa fresca da parte a área, o mesmo com um espaçamento maior entre linhas apresentou uma maior produtividade de alho-porró 0,50 × $0,10 \mathrm{~m}$, junto com o de $0,30 \times 0,15 \mathrm{~m}$. $\mathrm{O}$ tratamento que apresentou a menor produtividade foi o $0,50 \times 0,25 \mathrm{~m}$, pois o mesmo teve uma menor densidade de plantas por hectare, não apresentando competição entre plantas, tendo produtos de qualidade, com tamanhos e aparências desejadas pelos consumidores, porem apresentando uma perda de área que poderia ser utilizado para aumentar a produtividade.

O adensado apresentou maior produtividade de alho-porró, resultados semelhantes foi observado por Oliveira (2011), trabalhando com o desempenho do alface em diferentes espaçamentos, sob ambiente protegido e campo aberto, por Favorito et al. (2011) na cultura do manjericão, por Gomes et al. (2013) que trabalharam com o efeito do espaçamento no rendimento da chicória da Amazônia, por Lima et al. (2019) que trabalharão com o desempenho agronômico de jambu em função dos espaçamentos e arranjos espaciais. Segundo esses estudos, este fato ocorre devido que a produtividade está relacionada diretamente com a densidade de plantas por área.

Este espaço físico entre as plantas e linhas, induz ao crescimento e desenvolvimento de plantas daninhas que vão causar danos na fisiologia da produção da cultura principal (Batista et al., 2015). A influência de plantas daninhas não foi contabilizada durante o experimento, pois o manejo cultural foi realizado de forma continua, retirando todas as plantas manualmente que poderia prejudicar o alho-porró.

Desta forma, notasse que as menores densidade de plantio, contendo assim um número maior de plantas por área, mesmo que sofram uma competição, no final são favoráveis a produtividade, além de reduzir a infestação de plantas daninhas que possam prejudicar a cultura principal. Pode-se afirmar assim, que é necessário um manejo apropriado para manter uma máxima produtividade, pois o espaçamento adequado é uma condição determinante para que a planta possa expressar todo o seu potencial.

\section{Conclusão}

Para muitas culturas a produtividade é o principal fator a ser avaliado, porém para as hortaliças deve-se levar em consideração também as características físicas, tendo em vista que grande parte é consumida in natura. Portanto melhor espaçamento que se adapta para o alho-porró é aquele em que se tem uma boa produtividade e características físicas, os espaçamentos indicados para o cultivo são $0,50 \times 0,10 \mathrm{~m}$ e 0,30 x $0,15 \mathrm{~m}$.

\section{Referências}

Abade, M. T. R., Klosowski, É. S., Rocha, M. E. L., Coutinho, P. W. R., Souza, F. L. B., \& Barabasz, R. F. (2019). Morfometria de cultivares de rúcula sob telas de sombreamento e pleno sol na primavera. Agrometeoros, 27 (1), 217-226. http://dx.doi.org/10.31062/agrom.v27i1.26578.

Almeida, H. A. C., Silva, N. O., Silva, T. L., Fernandes, F. L., \& Sena, M. E. (2020). Características fisiológica, vegetativas e produtivas do rabanete em diferentes espaçamentos de plantio. Caderno de Ciências Agrárias, 12, 1-6. https://doi.org/10.35699/2447-6218.2020.16063.

Alvares, C. A., Stape, J. L., Sentelhas, P. C., Gonçalves, J. L. M., \& Sparovek, G. (2013). Köppen's climate classification map for Brazil. Meteorologische Zeitschrift, Stuttgart, 22 (6), 711-728. https://doi.org/10.1127/0941-2948/2013/0507.

Alves, T. N., Echer, M. M., Sackser, G. A. B., Black, A. V., Klosowski, É. S., Júnior, E. K. M., \& Coutinho, P. W. R. (2020). Desempenho produtivo da couve (Brassica oleracea L. var. acephala) consorciada com quiabeiro sob manejo orgânico. Research, Society and Development, 9 (12), p. e34891210943e34891210943, 2020. https://doi.org/10.33448/rsd-v9i12.10943. 
Azevedo, A. M., Andrade Júnior, V. C. D., Pedrosa, C. E., Fernandes, J. S. C., Valadares, N. R., Ferreira, M. A. M., \& Martins, R. A. D. V. (2012). Desempenho agronômico e variabilidade genética em genótipos de couve. Pesquisa Agropecuária Brasileira, 47 (12), 1751-1758. http://dx.doi.org/10.1590/S0100-204X2012001200011.

Batista, M. G., Galdez, J. M. S., Modesto, J. C. V., \& Ferreira, D. A. (2015). Análise fitossociológica de plantas daninhas na produção orgânica do jambu (Acmella oleracea L.). Cadernos de Agroecologia, 10 (3), 1-6.

Bezerra, F. T. C., Dutra, A. S., Bezerra, M. A. F., Oliveira Filho, A. F., \& Barros, G. L. (2014). Comportamento vegetativo e produtividade de girassol em função do arranjo espacial das plantas. Revista Ciência Agronômica, 45 (2), 335-343. https://doi.org/10.1590/S1806-66902014000200015.

Costa, M. R., Guimarães, M. A., Lemos Neto, H. S.; Rabelo, J. S., Hendges, A. R. A. A., Viana, C. S., Sampaio, I. M. G., \& Mendes, I. P. B. (2020). Desempenho agronômico do rabanete em diferentes densidades populacionais. Brazilian Journal of Development, 6 (6), 35679. 35689. https://doi.org/10.34117/bjdv6n6-199.

Coutinho, P. W. R., Oliveira, P. S. R., Echer, M. M., Cadorin, D. A., \& Vanelli, J. (2017). Establishment of intercropping of beet and chicory depending on soil management. Revista Ciência Agronômica, 48 (4), 674-682. https://doi.org/10.5935/1806-6690.20170078

Coutinho, P. W., Echer, M. M., Oliveira, P. S., Dalastra, G. M., Cadorin, D. A., \& Vanelli, J. (2018). Productivity and Qualitative Characteristics of Varieties of Beets. Journal of Agricultural Science, 10 (6), 327-333. https://doi.org/10.5539/jas.v10n6p327.

Empresa Brasileira de Pesquisa Agropecuária - EMBRAPA. (2010). Catálogo Brasileiro de Hortaliças: Saiba como plantar e aproveitar 50 das espécies mais comercializadas no país. Brasília. Embrapa Hortaliças. 60 p.

Favorito, P. A., Echer, M. M., Offemann, L. C., Shlindwein, M. D., Colombare, L. F., Schineider, R. P., \& Hachmann, T. L. (2011). Características produtivas do manjericão (Ocimum basilicum L.) em função do espaçamento entre plantas e entre linhas. Revista Brasileira de Plantas Medicinais, 13 , 582-586. https://doi.org/10.1590/S1516-05722011000500013.

Ferreira, D. F. Sisvar: a computer analysis system to fixed effects split plot type designs. Revista Brasileira de Biometria, 37 (4), 529-535, 2019. https://doi.org/10.28951/rbb.v37i4.450.

Filgueira, F. A. R. (2013). Novo manual de olericultura: Agrotecnologia moderna na produção e comercialização de hortaliças. 3 ed. Viçosa: UFV. 421 p.

Gomes, R. F., Silva, J. P., Gusmão, S. A. L., \& Souza, G. T. (2013). Produção de chicória da Amazônia cultivada sob densidade de cultivo e poda do pendão floral. Revista caatinga, 26 (3), 9 - 14. https://periodicos.ufersa.edu.br/index.php/caatinga/article/view/2573/pdf_50.

Kiffo, B. L., Tsadik, K. W., \& Tana, T. (2016). Yield and yield components of leek (Allium ampeloprasum var. porrum L.) as influenced by levels of nitrogen fertilizer and population density at Areka, Southern Ethiopia. Journal of Biology, Agriculture and Healthcare, 6 (15), 21-33.

Lima, S., Rosário, I. C., Silva, A., Arruda, R., \& Gomes, R. (2019). Desempenho agronômico de jambu (Acmela oleracea (L.) RK Jansen) em função de espaçamentos $\quad$ a $\quad$ espaciais. Enciclopédia $\quad$ Biosfera, 16 http://www.conhecer.org.br/enciclop/2019a/agrar/desempenho\%20agronomico.pdf.

Oliveira, R. G., Rodrigues, L. F. O. S., Seabra Junior, S., Silva, M. B., Nohama, M. T. R., Inagaki, A. M., \& Nunes, M. C. M. (2011). Comportamento de cultivares de alface em diferentes espaçamentos sob o cultivo protegido e campo aberto. Horticultura Brasileira, 29 (2), 110-118. http://www.abhorticultura.com.br/EventosX/Trabalhos/EV_5/A3661_T6418_Comp.pdf.

Raij, B. (2011). Fertilidade do solo e manejo de nutrientes. Piracicaba: Internacional Plant Nutrion Institute (IPNI). 420p.

Resende, G. M., Yuri, J. E., Costa, N. D., \& Mota, J. H. (2016). Yield of carrot cultivars in organic farming system at high temperature. Horticultura Brasileira, 34 (1), 121-125. https://doi.org/10.1590/S0102-053620160000100018.

Sampaio, I. M. G., Guimarães, M. A., Lemos Neto, H. S., Maia, C. L., Viana, C. S., \& Gusmão, S. A. L. (2018). Pode o uso de mudas agrupadas e a maior densidade de plantio aumentar a produtividade de jambu? Revista de Ciências Agrárias Amazonian Journal of Agricultural and Environmental Sciences, 61, 1-8. http://dx.doi.org/10.22491/rca.2018.2906.

Stavělíková, H. (2008). Morphological characteristics of garlic (Allium sativum L.) genetic resources collection - Information. Horticultural Science, 35, 130135. https://www.agriculturejournals.cz/publicFiles/01886.pdf

Taiz, L., Zeiger, E., Møller, I. M., \& Murphy, A. (2017). Fisiologia e desenvolvimento vegetal. 6 ed. Porto Alegre: Artmed.

Vasconcelos, U. A. A., Costa, C. C., Oliveira, M. N., Barbosa, J. W. S., Medeiros, A. B., \& Sobrinho, T. G. (2017). Efeito residual do esterco ovino no cultivo da alface em diferentes espaçamentos. Revista Verde de Agroecologia e Desenvolvimento Sustentável, 12 (3), 508511. https://doi.org/10.18378/rvads.v12i3.4901.

Vidigal, S. M., Lopes, I. P. C., \& Pereira, P. R. G. (2020). Produtividade de repolho cultivado em diferentes densidades populacionais. Brazilian Journal of Development, 6 (11), 86015-86027. https://doi.org/10.34117/bjdv6n11-137.

Yousaf, Z., Shinwari, Z. H., Qureshi, R. A., Khan, M. A., \& Gilani, S. S. (2004). Can complexity of the genus Allium L., be resolved through some numerical techniques? Pakistan Journal of Botany, 36 (3), 487-501, 2004. 